Thorax (1963), 18, 1

\title{
Immediate and late effects of pulmonary embolism by large thrombi in dogs
}

\author{
ROBERT MARSHALL, D. C. SABISTON ${ }^{1}$, P. R. ALLISON, \\ A. R. BOSMAN ${ }^{2}$, AND M. S. DUNNILL \\ From the Nuffield Department of Surgery and the Department of Pathology, \\ Radcliffe Infirmary, Oxford
}

Large radio-opaque clots introduced into the pulmonary circulation of anaesthetized dogs cause no reflex cardiovascular or respiratory disturbance at the time of impaction in the pulmonary arteries, and subsequent radiographs of the chest and histological studies show rapid absorption of the clot (Allison, Dunnill, and Marshall, 1960). The structure of a thrombus formed in a blood vessel in vivo in the presence of flowing blood is different from that of a clot formed in a test tube. Whereas a clot consists of a fibrin mesh enclosing red cells, a thrombus consists mainly of layers of fibrin and platelets. The immediate effect of impaction and the natural history of a thrombus might be different from that of a clot. The present study was undertaken to observe the effects of embolization by large thrombi in dogs and to follow the changes in lung function over the succeeding days. Information was also sought on methods which could be used to detect the occurrence of pulmonary embolism in man.

\section{METHODS}

Mongrel dogs of 10 to $19.5 \mathrm{~kg}$. were used. For the operative procedures and for the breathing tests they were premedicated with morphine, $1 \cdot 1 \mathrm{mg}$. $/ \mathrm{kg}$., and chlorpromazine, $1.0 \mathrm{mg} . / \mathrm{kg}$., and anaesthetized with pentobarbitone. Thrombi were produced in the inferior venae cavae by painting the wall of the vessel with pure phenol. The inferior vena cava was exposed through a mid-line abdominal incision, and all tributaries but one between the iliac veins and the renal veins were tied off. A small polythene catheter was passed through the remaining tributary into the inferior vena cava and tied into place. A clamp was placed across the inferior vena cava just above the iliac veins, the inferior vena cava was emptied of blood, and another clamp was placed just below the renal veins. One millilitre of pure phenol was introduced into the inferior vena cava through the poly-

\footnotetext{
1 Assistant professor of surgery, Johns Hopkins Hospital
}

2 Nuffield Foundation Dominion travelling fellow thene catheter, massaged around the lumen for one minute, and then withdrawn. The vessel was washed out with several changes of saline, the catheter was removed, and the clamps were released. Studies on another series of dogs have shown that after phenol treatment of the inferior vena cava thrombus formation is present by the following day and usually causes occlusion of the vein in five days (Sheil and Sabiston, to be published). Twenty dogs were used in the present series. A large thrombus was produced in the inferior vena cava after one application of phenol in 11 dogs, and in a further three dogs a second application was required to produce the thrombus. In six dogs only a thread-like thrombus was produced and the experiments were not continued. Of the 14 dogs in which a good thrombus was formed, follow-up breathing tests were not made on the first three, mainly because bronchospirometric studies at the time when the clot was passed on did not show any appreciable changes in differential oxygen uptake. In these dogs the thrombus was passed up into the inferior vena cava without the use of an introducer and may either have lodged temporarily in the inferior vena cava or may have broken up as a result of the handling. Two dogs died as a result of massive pulmonary embolism, one about one hour after the thrombus was passed on and the other whilst being anaesthetized on the following day. One dog died under anaesthesia one week after the inferior vena cava had been treated with phenol. Satisfactory followup studies were made on eight of the 20 dogs.

The breathing tests which were carried out on the dogs were as follows. With a cuffed endotracheal tube in position, the functional residual capacity was measured using a closed-circuit helium method. The diffusing capacity for carbon monoxide (DLoo) was measured using a single breath method modified from that of Ogilvie, Foster, Blakemore, and Morton (1957). The endotracheal tube was connected through a threeway tap to a two-litre rubber bag contained in a 10-litre perspex box. A measured volume of the $\mathrm{CO}-\mathrm{He}$ mixture was put into the bag. During an expiratory pause the endotracheal tube was connected through to the bag, and the dog's lungs were inflated by forcing about 1 litre of air into the box from a brass pump. The inflating pressure was measured 
by an anaeroid gauge. The lungs were kept inflated for about 15 seconds and then were allowed to expire into an empty rubber bag. The volume of gas inspired was measured as the difference between the volume of gas put into and the volume of gas remaining in the inspiratory bag. The volume of the expired gas and its carbon monoxide and helium concentrations were measured and the latter corrected for dilution by dead space gas. From these concentrations, the breath-holding time, the functional residual capacity of the lungs, and the intrapulmonary pressure during breath-holding, the single-breath DLoo was calculated.

In order to investigate the effect of embolism on the end-tidal, arterial $\mathrm{PCO}_{2}$ difference (Severinghaus and Stupfel, 1957), samples of arterial blood were taken by femoral puncture and end-tidal samples were taken through a small polythene cannula from just above the lower end of the endotracheal tube. Cross-wires were used to break up the axial flow of gas before the sampling point, and samples were taken by syringe, 2 to $3 \mathrm{ml}$. per breath, at the end of expiration. The end-tidal samples were analysed in the Scholander apparatus, and the arterial $\mathrm{PCO}_{2}$ was measured with the Severinghaus $\mathrm{PCO}_{2}$ electrode. Because of its possible clinical application, indirect estimates of the arterial $\mathrm{PCO}_{2}$ were also made by the rebreathing method (Hackney, Sears, and Collier, 1958 ; Marshall, 1958), subtracting an arbitrary $6 \mathrm{~mm}$. $\mathrm{Hg}$ from the mixed venous $\mathrm{PCO}_{2}$ to give an estimate of the arterial $\mathrm{PCO}_{2}$.

Bronchospirometry was carried out using a tube similar in design to that described by Frenckner and Björkman (1937) for use in man (Fig. 1). It is made of straight $\mathrm{D}$ section brass tube soldered together along the flat. The distal end of the left bronchial tube is of $\frac{5}{16}$ in. internal diameter round section and has a rubber cuff which can be inflated through a small tube lying alongside the D tubes. A tracheal cuff surrounding the lower end of the $D$ tubes can similarly be inflated. The proximal end of the tubes is closed by an airtight plug held in place by a spring clip, and side tubes are provided for connexion to the breathing apparatus. The hinged carinal hook can be pushed out by partial inflation of the left bronchial balloon. By the use of a bronchoscope light on a long carrier passed down the left tube, the orifice of the left upper lobe bronchus can be seen and the tube can be placed as close as possible to this bronchus without blocking it off. Using this bronchospirometry tube, differential recordings of oxygen uptake were made with twin closed-circuit spirometers. In addition to the direct kymographic recordings, volume changes were also recorded from a cathode ray oscilloscope by the use of precision low torque potentiometers rotated by the spirometer cords. Intrathoracic pressure changes were measured by a long oesophageal balloon and capacitance manometer. Two methods of recording were used. Each beam of a double beam oscilloscope was deflected on the $\mathrm{Y}$ axis by the volume signal from one of the spirometers whilst both beams were equally deflected on the $X$ axis by the intra-oesophageal pressure signal. In this way simultaneous pressurevolume loops of the two lungs were obtained. In the other method of recording, a single beam was deflected along the $Y$ axis by the signal from the right spirometer and along the $X$ axis by the signal from the left spirometer. With this system of recording, a measure of the relative compliance of the lungs could be made independent of any intra-oesophageal artefact. Changes in the width of the loop indicate relative changes in the airway resistance of the two lungs. Although the airway resistance of the apparatus, comprising bronchospirometry tube, three-way tap, and connexions, was $15 \mathrm{~cm}$. water $/ \mathrm{l}$. $/ \mathrm{sec}$. at $0.25 \mathrm{l}$./ $/ \mathrm{sec}$. on each side, small changes in the airway resistance of the dog caused widening of the right volume-left volume loop.

Measurements of functional residual capacity, DLco, end-tidal and arterial $\mathrm{PcO}_{2}$, and bronchospirometry were made on one or more occasions before the inferior vena cava was treated with phenol and again just before the thrombus was liberated. These preliminary measurements were made as baseline studies and with the hope of detecting any change in lung function which might occur during the period that the thrombus was forming. While a thrombus was forming small platelet or fibrin emboli might be detached and impact in the lungs.

At a second laparotomy the thrombus, which had formed in the inferior vena cava, was separated from the vein wall by blunt dissection. The thrombus was released at periods varying from seven to 14 days after the vena cava had been treated with phenol. Before the laparotomy the pulmonary artery pressure was measured by cardiac catheterization and the breathing tests were repeated. Bronchospirometric tracings were recorded continuously before, during, and after the operative procedures. The electrocardiogram (E.C.G.), central venous pressure, and, in some instances, arterial pressure, were also recorded during the time that the thrombus was passed on. The thrombus, after being freed from the vein, was placed in an introducer, a brass cannula of $9 \mathrm{~mm}$. internal diameter fitted with a plunger, and passed up the proximal end of the inferior vena cava towards the heart. During the period before and after the thrombus was passed into the circulation, all packs were removed from the

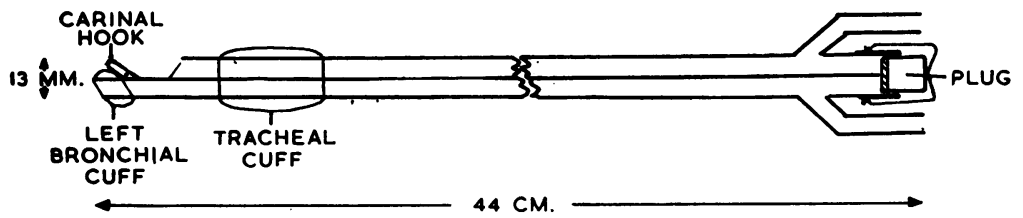

FIG. 1. Diagram of donble lumen bronchospirometry tube. 
upper abdomen so as to interfere as little as possible with the respiratory tracings. The vena cava was either ligatured or sutured and the abdomen was closed. Bronchospirometric tracings were continued for one or two hours after the operative procedures, and finally the measurements of functional residual capacity, DLco, and end-tidal and arterial $\mathrm{PcO}_{2}$ were repeated. The breathing tests, including bronchospirometry, were repeated at about one, three, 10, and 15 days after the embolization. On the day of the final test the pulmonary artery pressure was again measured. The dog was killed by bleeding, and the whole dog was perfused with formol saline before removal of the heart and lungs.

\section{RESULTS}

IMMEDIATE EFFECTS OF EMBOLIZATION The following effects were noted.

Cardiovascular system In none of the dogs in which recordings were made did embolism produce any effect on the E.C.G., femoral artery pressure, or central venous pressure during the minutes after the clot was passed into the lungs, although in most of the dogs the bronchospirometry records showed that the thrombus had impacted in the pulmonary artery.

Oxygen uptake and respiration In the 10 dogs in which bronchospirometry records were taken at the time of release of the thrombus the differential oxygen uptake indicated that in eight dogs the thrombus had obstructed one of the pulmonary arteries within a few seconds of release (Table I). In $\operatorname{dog} 8$ there was no change in the differential bronchospirometry for at least two hours. This thrombus produced no changes in the E.C.G. or central venous pressure at the time that it was passed on, and it is possible that it may have been delayed for over two hours in its passage to the pulmonary arteries. When the dog died the following day the thrombus was found in the main pulmonary artery. In dog 10 there was no change in the differential oxygen uptake for 15 minutes after the thrombus was passed on, but 30 minutes later, after the abdomen had been closed, the right pulmonary artery was partially obstructed. Dog 7 died one hour after the thrombus had been inserted. This thrombus immediately stopped oxygen uptake on the right side, and the respiratory rate increased for about one minute and then became slower than before. Recordings of vascular pressures and an E.C.G. were not made in this dog at the time that the thrombus was passed on. Of the nine dogs in which a change in differential oxygen uptake was seen, the uptake was reduced on the right side in eight and on the left side in one. Although the thrombus abolished the oxygen uptake on the right side in $\operatorname{dog} 7$, at necropsy the thrombus almost filled the main pulmonary artery. Figure 2 shows the percentage of oxygen uptake in the embolized lung in the eight dogs in which the recovery of lung function was followed.

The diffusing capacity The results of the measurements of $D_{L_{c o}}$ are shown in Table II and the mean value is given in Figure 2. Repeated measurements over several weeks before the embolus was passed into the lungs often showed a fall in diffusing capacity for carbon monoxide. In some instances this was no doubt associated with lung infection or collapse secondary to the anaesthesia but in others the cause was not obvious. It could have been due to an infection or collapse which went unnoticed, but a contributory factor might have been the impaction of small emboli which were detached from the main thrombus during its formation. At necropsy in two dogs small emboli were found which may have been detached from the main thrombus during its formation.

TABLE I

THE EFFECT OF PULMONARY EMBOLISM ON THE DIFFERENTIAL OXYGEN UPTAKE OF THE LUNGS

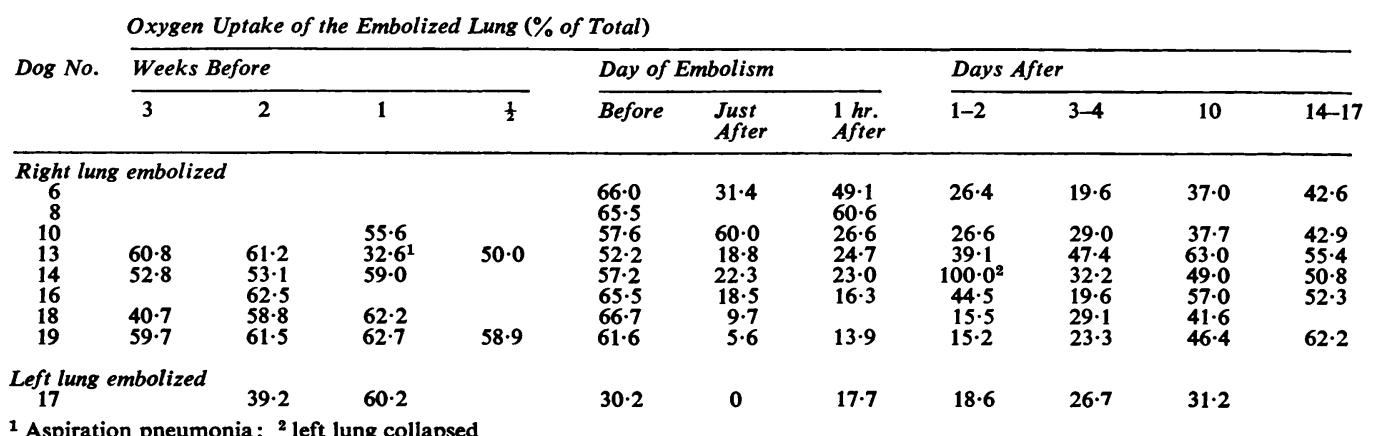

1 Aspiration pneumonia; ${ }^{2}$ left lung collapsed 
TABLE II

THE EFFECT OF PULMONARY EMBOLISM ON THE DIFFUSING CAPACITY OF THE LUNGS

\begin{tabular}{|c|c|c|c|c|c|c|c|c|c|c|}
\hline \multirow{3}{*}{ Dog No. } & \multicolumn{10}{|c|}{$D_{L c o}(\operatorname{ml} . / \min . / m m . H g)$} \\
\hline & \multicolumn{4}{|c|}{ Weeks Before } & \multicolumn{2}{|c|}{ Day of Embolism } & \multicolumn{4}{|c|}{ Days After } \\
\hline & 3 & 2 & 1 & $\frac{1}{2}$ & Before & After & $1-2$ & $3-4$ & 10 & 14-17 \\
\hline \multirow{8}{*}{$\begin{array}{r}6 \\
7 \\
8 \\
10 \\
13 \\
14 \\
15 \\
16 \\
17 \\
18 \\
19 \\
\text { Mean of } \\
10,13,14, \\
16,17,18,1\end{array}$} & & $8 \cdot 23^{2}$ & 0.382 & & $8 \cdot 31$ & $4 \cdot 20$ & $5 \cdot 23$ & 5.97 & $6 \cdot 18$ & $\overline{5.55}$ \\
\hline & & & $\begin{array}{r}9.38 \\
10 \cdot 57^{2}\end{array}$ & & $\begin{array}{l}8 \cdot 17 \\
9 \cdot 20\end{array}$ & 4.45 & & & & \\
\hline & & & $7 \cdot 38^{2}$ & & 6.50 & $\mathbf{3} \cdot \mathbf{4 2}$ & 5.58 & $7 \cdot 22$ & $7 \cdot 84$ & 6.84 \\
\hline & $\begin{array}{r}11 \cdot 82 \\
8 \cdot 29\end{array}$ & $\begin{array}{r}10 \cdot 41^{2} \\
5.35^{2}\end{array}$ & $\begin{array}{l}7.52^{1} \\
5.59^{2}\end{array}$ & $7 \cdot 48$ & $\begin{array}{l}7.50 \\
5.75\end{array}$ & $\begin{array}{l}5 \cdot 14 \\
3 \cdot 16\end{array}$ & $\begin{array}{l}5.65 \\
3.27\end{array}$ & $\begin{array}{l}5.76 \\
4.65\end{array}$ & $\begin{array}{l}6.68 \\
5.63\end{array}$ & $\begin{array}{l}6.41 \\
4.51\end{array}$ \\
\hline & $8 \cdot 67$ & $\begin{array}{l}7 \cdot 17^{2} \\
6 \cdot 52\end{array}$ & $\begin{array}{l}6 \cdot 68^{2} \\
6 \cdot 00^{2}\end{array}$ & & $\begin{array}{l}6.42 \\
5.55\end{array}$ & 4.03 & 4.45 & 3.98 & 4.52 & 5.95 \\
\hline & $9 \cdot 12$ & $\begin{array}{l}6 \cdot 14 \\
7.70^{2}\end{array}$ & $\begin{array}{l}7 \cdot 30^{2} \\
5 \cdot 58^{2}\end{array}$ & & $\begin{array}{l}5 \cdot 19 \\
6.02\end{array}$ & $\begin{array}{l}3 \cdot 10 \\
4 \cdot 50\end{array}$ & $\begin{array}{l}4.55 \\
3.17\end{array}$ & $\begin{array}{l}4.73 \\
4.86\end{array}$ & $\begin{array}{l}4.28 \\
6.46\end{array}$ & \\
\hline & $12 \cdot 38$ & $12 \cdot 18^{2}$ & $10 \cdot 41^{2}$ & $8 \cdot 32$ & 7.94 & 5.92 & $8 \cdot 21$ & $7 \cdot 56$ & 8.94 & $9 \cdot 17$ \\
\hline & & & $7 \cdot 11$ & & $6 \cdot 35$ & $4 \cdot 18$ & 4.98 & 5.54 & $6 \cdot 33$ & \\
\hline
\end{tabular}

${ }^{1}$ Aspiration pneumonia; ${ }^{2}$ inferior vena cava treated with phenol after this measurement was made

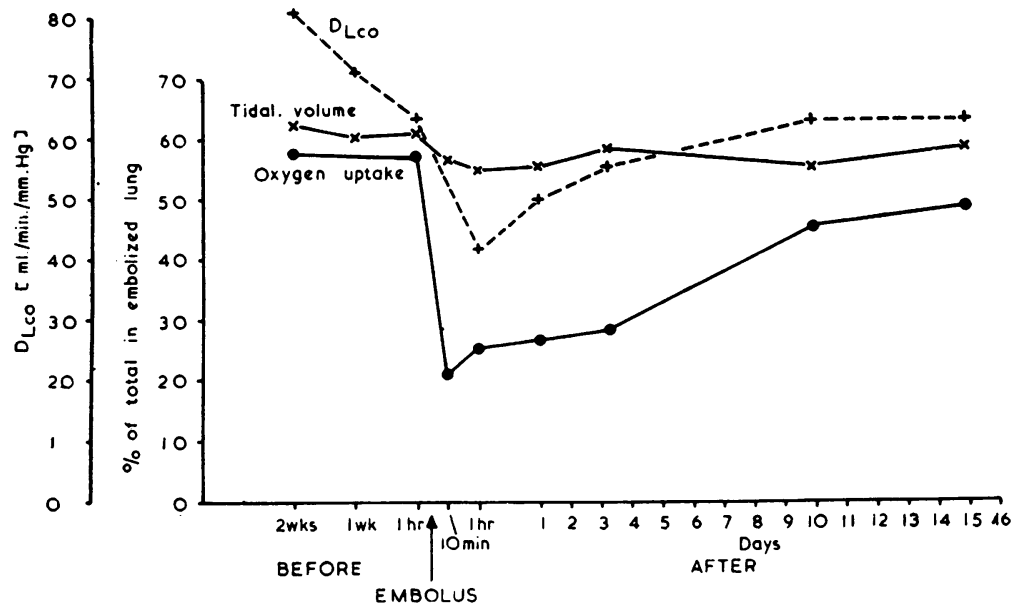

FIG. 2. Mean values for eight dogs of the $D_{\text {Lco }}$ of both lungs and the tidal volume and oxygen uptake of the embolized lung before and after the impaction of a thrombus in the pulmonary artery.

Mechanical properties of the lungs The changes in compliance of the lung were measured in two ways. First the absolute compliance of each lung was measured from the intra-oesophageal pressure tidal volume loops. Secondly, the tracings in which the tidal volume of each lung was plotted on coordinate axes showed that in all dogs the two lungs reached their inspiratory volume at the same time so that differential change of compliance between the right and left lungs was shown by the relative tidal volumes of the lungs. Caution is necessary in interpreting changes in compliance and relative tidal volumes because in some of the dogs the tidal volume on the left was relatively small when the total tidal volume was small and the proportion of the tidal volume contributed by the left side increased when the total tidal volume increased. The mean effect of the embolization on tidal volume is shown in Figure 2. The proportion of the tidal volume contributed by the affected lung was reduced by only $6 \%$ (Table III). Table IV shows the changes which occur in the absolute compliance of the lungs within two hours of the embolism. Except in $\operatorname{dog} 7$, in which the embolism was acutely fatal, the reduction in compliance in the two hours following embolism was small and may have been accounted for in part by the reduction in compliance which occurs in anaesthetized dogs with the passage of time. The compliance measured during the two weeks after the embolization did not show any significant difference from the control values.

The non-elastic resistance of the lungs was not measured directly, but changes in the relative nonelastic resistance of the two lungs could be detected by the opening of loops of the right tidal volume/ left tidal volume plot on coordinate axes. In some instances loops were present before the embolus 
TABLE III

THE EFFECT OF PULMONARY EMBOLISM ON THE DIFFERENTIAL TIDAL VOLUME OF THE LUNGS

Tidal Volume of the Embolized Lung (\% of Total)

\begin{tabular}{|c|c|c|c|c|c|c|c|c|c|c|c|}
\hline \multirow[t]{2}{*}{ Dog No. } & \multicolumn{4}{|c|}{ Weeks Before } & \multicolumn{3}{|c|}{ Day of Embolism } & \multicolumn{4}{|c|}{ Days After } \\
\hline & 3 & 2 & 1 & $\frac{1}{2}$ & Before & $\begin{array}{l}\text { Just } \\
\text { After }\end{array}$ & $\begin{array}{l}1 \mathrm{hr} . \\
\text { After }\end{array}$ & $1-2$ & $3-4$ & 10 & $14-17$ \\
\hline $\begin{array}{c}\text { Right } \\
6 \\
8 \\
10 \\
13 \\
14 \\
16 \\
18 \\
19\end{array}$ & $\begin{array}{l}70 \cdot 2 \\
62 \cdot 8 \\
64 \cdot 8 \\
58 \cdot 0\end{array}$ & $\begin{array}{l}70 \cdot 0 \\
63.8 \\
73.6 \\
57.0 \\
57.7\end{array}$ & $\begin{array}{l}61 \cdot 4 \\
41 \cdot 3^{1} \\
62 \cdot 6 \\
68 \cdot 2 \\
62 \cdot 4\end{array}$ & $\begin{array}{l}56 \cdot 0 \\
55.6\end{array}$ & $\begin{array}{l}72 \cdot 8 \\
56 \cdot 3 \\
64 \cdot 0 \\
63 \cdot 0 \\
60 \cdot 0 \\
74 \cdot 0 \\
61 \cdot 0 \\
64 \cdot 4\end{array}$ & $\begin{array}{l}72 \cdot 4 \\
70 \cdot 0 \\
49 \cdot 8 \\
55 \cdot 3 \\
68 \cdot 8 \\
56 \cdot 7 \\
56 \cdot 2\end{array}$ & $\begin{array}{l}66 \cdot 4 \\
55 \cdot 3 \\
56 \cdot 2 \\
57 \cdot 6 \\
52 \cdot 9 \\
62 \cdot 7 \\
57 \cdot 3\end{array}$ & $\begin{array}{c}55 \cdot 3 \\
68 \cdot 0 \\
69 \cdot 2 \\
100 \cdot 0^{2} \\
65 \cdot 6 \\
55 \cdot 4 \\
54 \cdot 2\end{array}$ & $\begin{array}{l}56 \cdot 2 \\
58 \cdot 8 \\
62 \cdot 9 \\
69 \cdot 8 \\
73 \cdot 1 \\
62 \cdot 9 \\
56 \cdot 2\end{array}$ & $\begin{array}{l}56 \cdot 2 \\
65 \cdot 4 \\
62 \cdot 6 \\
63 \cdot 8 \\
54 \cdot 6 \\
58 \cdot 4 \\
51 \cdot 1\end{array}$ & $\begin{array}{l}54 \cdot 6 \\
63 \cdot 2 \\
68 \cdot 7 \\
69 \cdot 1 \\
66 \cdot 6 \\
62 \cdot 6\end{array}$ \\
\hline $\begin{array}{l}\text { Left } \\
17\end{array}$ & emb & 36.6 & 20.9 & & $28 \cdot 6$ & $24 \cdot 2$ & 30.8 & $21 \cdot 9$ & $30 \cdot 2$ & 31.6 & \\
\hline
\end{tabular}

TABLE IV

EFFECT OF PULMONARY EMBOLISM ON THE COMPLIANCE OF THE LUNGS

Compliance (ml./cm. water)

\begin{tabular}{|c|c|c|c|c|c|c|}
\hline \multirow{3}{*}{$\begin{array}{l}\text { Dog } \\
\text { No. }\end{array}$} & \multicolumn{3}{|c|}{ Right Lung } & \multicolumn{3}{|c|}{ Left Lung } \\
\hline & \multirow{2}{*}{$\begin{array}{l}\text { Before } \\
\text { Embolus }\end{array}$} & \multicolumn{2}{|c|}{ After Embolus } & \multirow{2}{*}{$\begin{array}{l}\text { Before } \\
\text { Embolus }\end{array}$} & \multicolumn{2}{|c|}{ After Embolus } \\
\hline & & $2 \mathrm{~min}$. & $1-2 \mathrm{hr}$. & & $2 \mathrm{~min}$. & 1-2 hr. \\
\hline $\begin{array}{r}6 \\
7 \\
8 \\
10 \\
13 \\
14 \\
16 \\
17 \\
18 \\
19\end{array}$ & $\begin{array}{l}23 \cdot 0 \\
17 \cdot 8 \\
22.9 \\
17 \cdot 3 \\
19 \cdot 9 \\
14 \cdot 5 \\
16 \cdot 3 \\
15 \cdot 3 \\
16.9 \\
32 \cdot 5\end{array}$ & $\begin{array}{r}18.2 \\
5.1 \\
19.5 \\
19.3 \\
14.0 \\
13.8 \\
15.0 \\
15.3 \\
18.7 \\
34.1\end{array}$ & $\begin{array}{l}18.4 \\
17 \cdot 7 \\
17 \cdot 7 \\
19 \cdot 1 \\
12.5 \\
13.0 \\
14 \cdot 0 \\
14.0 \\
28.7\end{array}$ & $\begin{array}{r}10.2 \\
11.8 \\
16.9 \\
8.5 \\
11.7 \\
10.7 \\
3.7 \\
5.9 \\
9.9 \\
20.2\end{array}$ & $\begin{array}{r}12 \cdot 1 \\
9.0 \\
15.1 \\
8 \cdot 3 \\
11.8 \\
9.8 \\
5.6 \\
4.8 \\
12.7 \\
21 \cdot 2\end{array}$ & $\begin{array}{c}10 \cdot 8 \\
13 \cdot 8 \\
13 \cdot 1 \\
13 \cdot 4 \\
9 \cdot 3 \\
7 \cdot 1 \\
6 \cdot 1 \\
11 \cdot 8 \\
20.0\end{array}$ \\
\hline
\end{tabular}

was passed on. These loops were nearly always in an anti-clockwise direction, that is, the resistance to airflow was relatively increased on the right. As a result of the embolization there was an appearance of a loop or widening of the loops in only three of the 10 dogs. Widening of the loops was seen in some of the follow-up measurements but was due to secretions in the airways.

Functional residual capacity Small changes in functional residual capacity (F.R.C.) resulting from embolization could not be measured by the method used. The standard deviation of measurements of volumes by the apparatus used was $\pm 14 \mathrm{ml}$. The F.R.C. of each lung was not measured separately, but the total F.R.C. was significantly reduced on the day of embolization in only three of eight dogs. In dog 7 the reduction of F.R.C. was apparent from the spirometer tracing (Fig. 4). In one dog there was a significant increase in F.R.C. On the day after the embolization the F.R.C. was significantly reduced in only one dog in which the left lung had become consolidated.

$\mathrm{PCO}_{2}$ Some of the measurements of arterial $\mathrm{PCO}_{2}$ made on the dogs early in the series had to be discarded because the dog's temperature was not measured at the time that the arterial blood sample was taken. On some occasions, particularly after laparotomy, the temperature fell as low as $33^{\circ} \mathrm{C}$. Satisfactory measurements of arterial $\mathrm{PCO}_{2}$, followed closely by mixed venous $\mathrm{PCO}_{2}$, were made on 39 occasions in seven dogs. If a comparison is made only between those measurements, 17 in number, before the thrombus was moved on, the values are: mixed venous $\mathrm{PCO}_{2}-6=56.7 \mathrm{~mm}$. $\mathrm{Hg}$, arterial $\mathrm{PCO}_{2}=56.8 \mathrm{~mm}$. Hg, S.D. of the differences $\pm 2.78 \mathrm{~mm}$. $\mathrm{Hg}$. This comparison is considerably affected by the last two measurements made on dog 19 before the thrombus was moved on. If these results are omitted, on the assumption that some pathological change may have occurred, the values are : mixed venous $\mathrm{PCO}_{2}-6=58.3 \mathrm{~mm}$. $\mathrm{Hg}$, arterial $\mathrm{PCO}_{2}=57 \cdot 7 \mathrm{~mm}$. Hg, S.D. of the differences $\pm 2.06 \mathrm{~mm}$. Hg. Dog 19 showed wide discrepancies between mixed venous $\mathrm{PCO}_{2}-6$ and arterial $\mathrm{PCO}_{2}$ on four oscasions, and the reason for this is not apparent. In the 31 measurements on the other six dogs, both before and after the embolism, only one difference greater than $4.2 \mathrm{~mm}$. $\mathbf{H g}$ was found, and this difference of $10.5 \mathrm{~mm}$. $\mathrm{Hg}$ occurred when one lung was completely collapsed. In the other 30 measurements on these six dogs the mean mixed venous $\mathrm{PCO}_{2}-6$ was $55.3 \mathrm{~mm}$. $\mathrm{Hg}$ and the mean arterial $\mathrm{PCO}_{2}$ was $54.9 \mathrm{~mm}$. $\mathrm{Hg}$, S.D. of the differences $\pm 2.54 \mathrm{~mm}$. $\mathrm{Hg}$. Thus in these dogs the occurrence of a pulmonary embolism did not affect the estimation of arterial $\mathrm{PCO}_{2}$ derived from the mixed venous $\mathrm{PCO}_{2}$.

The results of the arterial, end-tidal $\mathrm{PCO}_{2}$ differences in the five dogs in which satisfactory 
TABLE V

THE EFFECT OF PULMONARY EMBOLISM ON THE ARTERIAL, END-TIDAL $\mathrm{P}_{\mathrm{CO}_{2}}$ DIFFERENCE

\begin{tabular}{|c|c|c|c|c|c|c|c|c|c|}
\hline \multirow{3}{*}{$\begin{array}{l}\text { Dog } \\
\text { No. }\end{array}$} & \multicolumn{9}{|c|}{ Arterial, End-tidal $\mathrm{Pco}_{2}(\mathrm{~mm} . \mathrm{Hg})$} \\
\hline & \multicolumn{3}{|c|}{ Weeks Before } & \multicolumn{6}{|c|}{ Day of Embolism Days After } \\
\hline & 3 & 2 & 1 & Before & After & $1-2$ & $3-4$ & 10 & $14-17$ \\
\hline $\begin{array}{l}14 \\
16 \\
17 \\
18 \\
19\end{array}$ & $\begin{array}{r}10 \cdot 6 \\
6 \cdot 8\end{array}$ & $\begin{array}{r}1.6 \\
5.2 \\
6.1 \\
15.4 \\
6.8\end{array}$ & $\begin{array}{r}4 \cdot 4 \\
11 \cdot 4^{1} \\
5 \cdot 5 \\
4 \cdot 2 \\
10 \cdot 3\end{array}$ & $\begin{array}{r}3.4 \\
3.8 \\
6.7 \\
13.0 \\
9.4\end{array}$ & $\begin{array}{r}6.5 \\
11.0 \\
9.1 \\
12.0 \\
13.7\end{array}$ & $\begin{array}{c}17.8^{1} \\
9.9 \\
7.8 \\
12.0\end{array}$ & $\begin{array}{r}2 \cdot 0 \\
7 \cdot 9 \\
14 \cdot 3 \\
8.5 \\
12.7\end{array}$ & $\begin{array}{r}8 \cdot 7 \\
4.8 \\
7 \cdot 4 \\
14.2 \\
3 \cdot 7\end{array}$ & $\begin{array}{l}1.4 \\
7.7\end{array}$ \\
\hline Mean & & $7 \cdot 0$ & $7 \cdot 1$ & $7 \cdot 3$ & $10 \cdot 5$ & & $9 \cdot 1$ & $7 \cdot 8$ & \\
\hline
\end{tabular}

repeated measurements were made are shown in Table $\mathrm{V}$. The differences in the control period are larger than those reported by Julian, Travis, Robin, and Crump (1960). Although this difference did increase in four dogs as a result of the embolism, the rise was small in comparison with the magnitude of the change in oxygen uptake produced by the embolus. The largest increases in arterial, end-tidal $\mathrm{PCO}_{2}$ difference which occurred before the thrombus was passed into the lung were associated with a collapse of part of the lung.

RECOVERY OF LUNG FUNCTION AFTER THE EMBOLIZATION The following results were obtained.

Oxygen uptake The proportion of the oxygen which is taken up in the embolized lung is shown in Table I and the mean values in Figure 2. In the seven dogs which were followed up and in which the embolus went to the right lung the mean proportion of the oxygen uptake due to the right lung fell from $61 \%$ to $18.6 \%$, i.e., $30 \%$ of the original uptake of the right lung, within one hour after the embolization. The function recovered to give an uptake of $49.7 \%$ of the total, $81 \%$ of the original uptake of the right lung, by 14 to 16 days after the embolization. For comparison, Figure 3 shows the recovery of oxygen uptake in three dogs in which fresh clots were passed into the pulmonary artery (Allison et al., 1960). The recovery of function was rather more rapid than after embolization with the thrombi.

The diffusing capacity The rise in diffusing capacity for carbon monoxide after embolization occurred most rapidly in the first three days (Fig. 2), but a further increase took place over the following two weeks, by the end of which time the diffusing capacity had risen to a level comparable to that just before the thrombus was passed into the lungs.

Pulmonary vascular pressures The pulmonary artery pressures before and about two weeks after the embolization are shown in Table VI. A small rise of pressure occurred in some of the dogs but this is probably not significant.

\section{TABLE VI}

THE EFFECT OF PULMONARY EMBOLISM ON THE PULMONARY ARTERY PRESSURE

\begin{tabular}{lll} 
& \multicolumn{2}{c}{ Pulmonary Artery Pressure $(\mathrm{mm} . \mathrm{Hg})^{1}$} \\
\cline { 2 - 3 } Dog. No. & Before & Two Weeks After \\
\hline 6 & $15 / 0$ & $22 /-2$ \\
10 & $14 / 0$ & $15 / 0$ \\
13 & $17 / 6$ & $18 / 5$ \\
14 & $12 /-5$ & $16 / 6$ \\
16 & $8 / 0$ & $12 / 3$ \\
18 & $9 / 2$ & $16 / 4$ \\
19 & $19 / 10$ & $22 / 8$
\end{tabular}

1 The reference level of the pressure measurements was the highest part of the sternum with the dog supine,

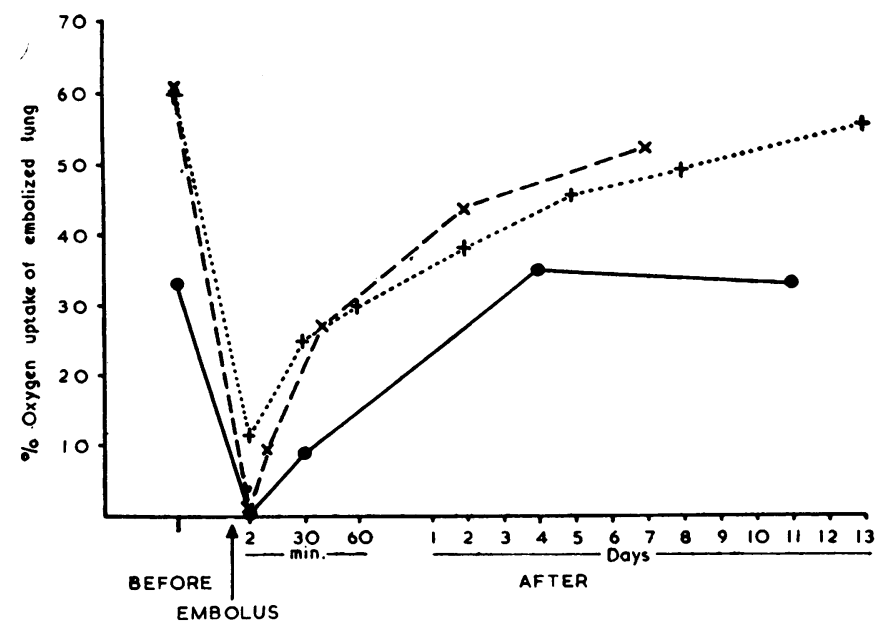

FIG. 3. Differential oxygen uptake of the embolized lung after the impaction of a fresh blood clot in the pulmonary artery. Results in three dogs. The right lung was involved in two dogs, the left lung (solid line) in one. 
PATHOLOGY In the dogs sacrificed about two weeks after the embolization a thrombus was found impacted at the bifurcation of a large pulmonary artery, usually in the lower lobe. The embolus was more compact than in the dogs into which a single large fresh blood clot had been introduced (Allison et al., 1960), and it had the laminated, heterogenous appearance of antemortem thrombus. Dilatation of the vasa vasorum was not nearly as prominent as in the dogs with an embolus of fresh blood clot, and the process of organization appeared to occur from within the vessel lumen. There was a striking increase in metachromatic material (sulphated mucopolysaccharide) in the media of the arteries adjacent to the point of attachment of the thrombus.

In three of the dogs examined the thrombus contained, in addition to fibrin, platelets, and red cells, several masses of discrete haematoxyphil material. The nature of this material is uncertain. It resembled small masses of bacteria but it failed to stain by Gram's method. It is reminiscent of organisms seen occasionally after treatment with antibiotics when staining properties may be altered. In three of the dogs there were pneumonic changes in the lungs, and in one dog an abscess was present. In the lung parenchyma of many of the dogs occasional small foci of cellular infiltration or minute abscesses were found. These were not confined to the lung or the lobe receiving the embolus, and may have been the result of repeated administration of anaesthetics.

\section{DISCUSSION}

One of the purposes of this investigation was to observe the immediate effects of and the recovery from pulmonary embolism produced by thrombi, which should be comparable to those formed in man post-operatively. After phenol has been applied to the inferior vena cava the thrombus has started to form by the following day and occlusion of the inferior vena cava is complete in five days. The thrombi in this investigation were six to 14 days old at the time of the embolization and can probably be compared to thrombi which have started in veins at the time of operation and have been released into the circulation about 10 days later.

There was an almost complete absence of cardiovascular or respiratory reflex effects when the large thrombi impacted in the pulmonary arteries. A similar lack of response had already been noted when large radio-opaque clots impacted in the pulmonary artery (Allison et al., 1960) of dogs similarly anaesthetized, although a small blood clot does give rise to a respiratory reflex under the same conditions (Marshall and Allison, 1962). In only one dog of the series was there any suggestion of reflex changes in respiration. This was in $\operatorname{dog} 7$, in which the main pulmonary artery was almost completely obstructed. In this dog the respiratory rate and the tidal volume increased for about one minute before the respiration slowed. This was the only dog which showed definite evidence of change in the F.R.C. as a result of the embolization. As the respiratory rate slowed, the right embolized lung continued to express air slowly during the time that the left lung was in an expiratory pause (Fig. 4).

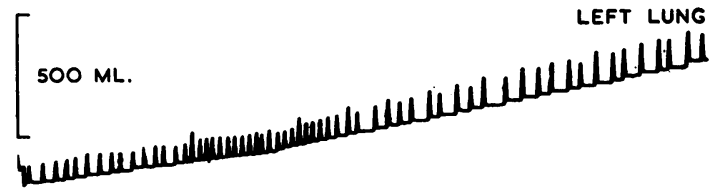

RIGHT LUNG

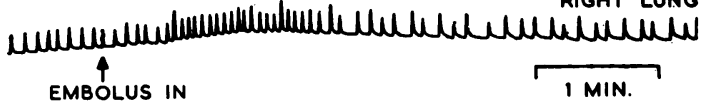

FIG. 4. Bronchospirometry tracing from $\operatorname{dog} 7$ at the time of impaction of the embolus.

At the time of embolization the dogs were breathing air enriched with 30 to $60 \%$ oxygen from spirometers. Binger, Brow, and Branch (1924) have suggested that the tachypnoea which follows large pulmonary emboli is due to anoxaemia and they have shown that it can be abolished or reduced by breathing oxygen. But in the present experiments the systemic blood pressure did not fall, and the increased oxygen tensions inspired could have produced very little change in the oxygen content of the arterial blood and very little improvement of tissue anoxia. The findings of de Takáts, Beck, and Fenn (1939) that liberation of clots formed in the femoral veins of 25 dogs caused death in all within five minutes are difficult to explain but the Martin's solution used to produce the clots may have been responsible.

Although there was no sudden reflex effect on respiration, there was always a gradual increase in total tidal volume with an accompanying fall in arterial $\mathrm{PCO}_{2}$. In all seven dogs in which it was measured, the mixed venous $\mathrm{PCO}_{2}$ fell as a result of the embolism ; the mean fall was $18.5 \mathrm{~mm}$. $\mathrm{Hg}$. The mean fall in arterial $\mathrm{PcO}_{2}$ in the five dogs in which it was measured was $15.8 \mathrm{~mm}$. $\mathrm{Hg}$. The reason for the increased ventilation is not known, but in these dogs the arterial oxygen tension was 
not measured and a fall in arterial oxygen tension, as reported by Stein, Forkner, Robin, and Wessler (1961), has not been excluded.

Changes in the compliance or airway resistance of the embolized lungs of these dogs were small and inconstant. Severinghaus, Swenson, Finley, Lategola, and Williams (1961) found changes in compliance and airway resistance in dogs in which one main pulmonary artery had been blocked by a balloon, but the shift of ventilation away from the blocked lung did not usually occur until the alveolar $\mathrm{CO}_{2}$ fell below 1.5 per cent. Since there was only a small shift of ventilation away from the embolized lung of the dogs in this series, one might expect to find larger arterial, end-tidal $\mathrm{PCO}_{2}$ differences. The expected arterial, end-tidal $\mathbf{P C O}_{2}$ difference can be calculated for a hypothetical case in which the two lungs are normally equally ventilated and perfused and in which a pulmonary embolus reduces the blood flow to one lung to one third, the cardiac output and the equal distribution of the ventilation remaining unchanged. The calculations have been made with the assistance of the ventilation and perfusion analysis methods of Rahn and Fenn (1955), and the effect of reinhalation of dead space gas has been neglected. If the reduced blood flow to the embolized lung is due to complete blockage of the vessels to two-thirds of the lung, the remaining vessels remaining patent, then the arterial, endtidal $\mathrm{PCO}_{2}$ difference would be $15 \mathrm{~mm}$. $\mathrm{Hg}$ with a mixed venous $\mathrm{PCO}_{2}$ of $50 \mathrm{~mm}$. $\mathrm{Hg}$, or $11 \mathrm{~mm}$. $\mathrm{Hg}$ if the mixed venous $\mathrm{PCO}_{2}$ had fallen to $34 \mathrm{~mm}$. $\mathrm{Hg}$ as a result of the hyperventilation. If, on the other hand, the reduced blood flow through the embolized lung is due to partial obstruction of the major branches of the pulmonary artery so that all parts of the lung received a reduced perfusion, then the arterial, end-tidal $\mathrm{PCO}_{2}$ difference would be only $4 \mathrm{~mm}$. $\mathrm{Hg}$ for a mixed venous $\mathrm{PCO}_{2}$ of $50 \mathrm{~mm}$. $\mathrm{Hg}$, or $3 \mathrm{~mm}$. $\mathrm{Hg}$ when the mixed venous $\mathrm{PCO}_{2}$ was $34 \mathrm{~mm}$. $\mathrm{Hg}$. In these experiments, and presumably in many cases of human pulmonary embolism, the thrombus was fairly firm and was probably able to cause partial blockage of a main pulmonary artery so that a reduced but general perfusion could continue.

As a result of the embolism the $\mathrm{DL}_{\mathrm{co}}$, in the dogs in which the embolus went to the right lung, fell from 6.54 to $4.36 \mathrm{ml} . / \mathrm{min} . / \mathrm{mm}$. $\mathrm{Hg}$, that is, by 34 per cent. In these dogs the oxygen uptake of the right side, and therefore presumably the DL $_{\text {oo }}$ of the right side (Bosman, Sabiston, and Marshall, to be published), was usually $60 \%$ of the total so that the above change in $\mathrm{DL}_{\mathrm{co}}$ could be accounted for by a fall in $\mathrm{DL}_{\mathrm{co}}$ of the right side to one-third of normal if the $\mathrm{DL}_{\text {co }}$ of the left side remained unchanged. Turino, Brandfonbrener, and Fishman (1959) have shown that when one pulmonary artery is blocked in man the diffusing capacity of the other lung does not increase. Assuming that this is also true for dogs, the change in $\mathrm{DL}_{\mathrm{co}}$ of the embolized lung can be calculated. When this is plotted against the change in oxygen uptake by the embolized lung, there is no positive correlation (Fig. 5). Turino et al. also found

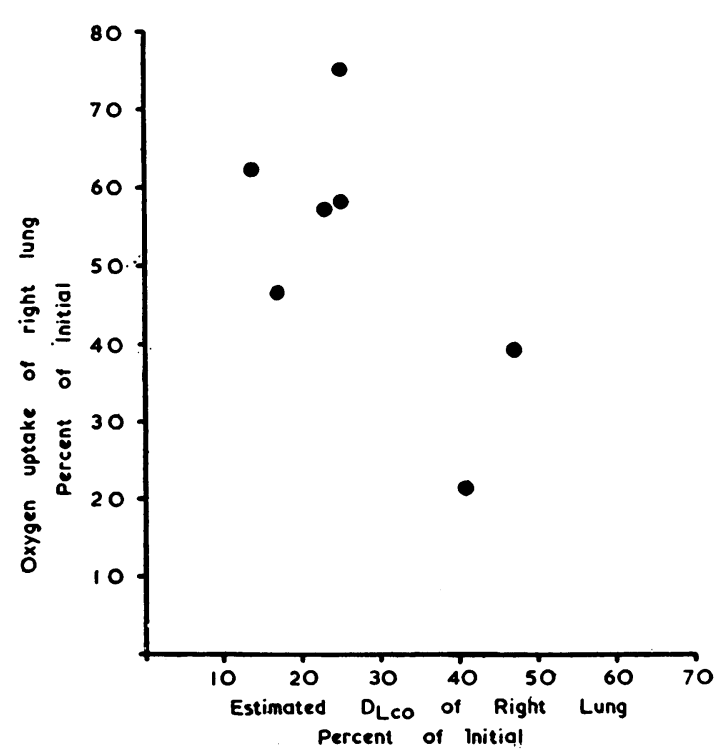

FIG. 5. The relationship between the reduction in oxygen uptake and the estimated reduction in diffusing capacity of the embolized lung. Results in seven dogs in which the embolus went to the right lung.

that partial blockage of a pulmonary artery reduced the diffusing capacity only when the oxygen uptake of that side was reduced below $50 \%$ of normal. The fall in $D_{L_{00}}$ in the present series of dogs could have been caused either by a general reduction in blood flow or by a complete obstruction of blood to parts of the lung. The change in diffusing capacity caused by the embolus was more striking than the change in arterial, end-tidal $\mathrm{PCO}_{2}$ difference. Changes in $\mathrm{DL}_{\text {co }}$ may be of help in the investigation of patients with pulmonary embolism but preliminary measurements are necessary and other causes of lowered diffusing capacity must be excluded.

The occluded lung had regained over $80 \%$ of its normal proportion of total lung function two weeks after the embolization, although considerable amounts of thrombus were found at necropsy. 
The recovery was somewhat slower than after the impaction of fresh blood clot, but there was nevertheless a surprising degree of recovery from thrombi which were one to two weeks old at the time of impaction. If the speed of absorption and recovery of function in man is comparable to that in the dog, there would appear to be no ill effects to be expected from leaving in situ pulmonary emboli which did not endanger life by obstructing blood flow in the first few days. This impression is supported by the clinical studies of Dunerr, Pernow, and Rignér (1960). The development of cor pulmonale is more likely after repeated emboli or in patients with underlying disease of the lungs (Ehrner, Garlind, and Linderholm, 1959).

\section{SUMMARY}

Pulmonary embolism was produced in dogs by thrombi which had been formed in the inferior venae cavae. Suitable thrombi were produced in 14 of 20 dogs. Measurements of the differential oxygen uptake of the two lungs, lung mechanics, diffusing capacity for $\mathrm{CO}$, and end-tidal and arterial $\mathrm{PCO}_{2}$ were made before and at intervals for two weeks after the embolization.

The embolization produced no effects which could be attributed to reflex action but caused a fall in the $\mathrm{O}_{2}$ uptake of one lung, usually the right, to a mean value of $30 \%$ of the initial uptake. A similar fall was produced in the diffusing capacity for $\mathrm{CO}$, and both the diffusing capacity for $\mathrm{CO}$ and the $\mathrm{O}_{2}$ uptake had returned to about $80 \%$ of the initial value two weeks after the embolization.

The ventilation of the embolized lung decreased only slightly, but in spite of this there was no significant increase in the end-tidal, arterial $\mathrm{PCO}_{2}$ difference. The reason for this is discussed.

\section{REFERENCES}

Allison, P. R., Dunnill, M. S., and Marshall, R. (1960). Thorax, 15, 273.

Binger, C. A. L., Brow, G. R., and Branch, A. (1924). J. clin. Invest., $1,155$.

de Takáts, G., Beck, W. C., and Fenn, G. K. (1939). Surgery, 6, 339. Dunér, H., Pernow, B., and Rignér, K. G. (1960). Acta med. scand., $168,381$.

Ehrner, L., Garlind, T., and Linderholm, H. (1959). Ibid., $164,279$.

Frenckner, P., and Björkman, S. (1937). Proc. roy. Soc. Med., 30, 477.

Hackney, J. D., Sears, C. H., and Collier, C. R. (1958). J. appl. Physiol., 12, 425.

Julian, D. G., Travis, D. M., Robin, E. D., and Crump, C. H. (1960). Ibid., 15, 87.

Marshall, R. (1958). J. clin. Invest., 37, 394.

and Allison, P. R. (1962). Thorax, 17, 289.

Ogilvie, C. M., Forster, R. E., Blakemore, W. S., and Morton, J. W. (1957). J. clin. Invest., 36, 1.

Rahn, H., and Fenn, W. O. (1955). A graphical analysis of the respiratory gas exchange; the $\mathrm{O}_{2}-\mathrm{CO}_{2}$ diagram. American Physiological Society, Washington.

Severinghaus, J. W., and Stupfel, M. (1957). J. appl. Physiol., 10, 335.

, Swenson, E. W., Finley, T. N., Lategola, M. T., and Williams, J. (1961). Ibid., 16, 53.

Stein, M., Forkner, C. E., Robin, E. D., and Wessler, S. (1961). Ibid., $16,488$.

Turino, G. M., Brandfonbrener, M., and Fishman, A. P. (1959). J. clin. Invest., 38, 1186. 